\title{
Numerical analysis of laser welding with consideration analytical methods of determining phase transformations and mechanical properties of welded joint
}

\author{
Wiesława Piekarska ${ }^{1}$, Dorota Goszczyńska-Króliszewska ${ }^{1, *}$, Zbigniew Saternus ${ }^{1}$, \\ Tomasz Domański ${ }^{1}$, Marcin Kubiak ${ }^{1}$ \\ ${ }^{1}$ Institute of Mechanics and Machine Design Foundations, Czestochowa University of Technology, \\ Dabrowskiego 73, 42-200 Częstochowa, Poland, EU
}

\begin{abstract}
The numerical analysis of laser welding process with consideration analytical methods determining phase transformations and mechanical properties of welded joints are presents in this paper. The analytical CCT diagram and final structural composition of S355 steel are presented. The empirical relations presents in paper are determined by chemical compositions investigated steel and cooling rate between temperatures $800-500^{\circ} \mathrm{C}\left(\mathrm{t}_{8 / 5}\right)$. Phase composition and mechanical properties each of structures of steel in weld and heat affected zone (HAZ) are determined on the basis of analytical methods. Laser welded flat is used in numerical simulations in ABAQUS. Mathematical modes of volumetric welding source are used in the calculations. Temperature fields, shape and size of melting zone for selected points in the cross-section of the joint are determined on the basis of thermal cycles obtained numerical.
\end{abstract}

Keywords: CCT diagram, analytical methods, heat affected zone, numerical modelling, laser welding

\section{Introduction}

The increase of usefulness of laser welding technology in industries causes an increase of technological requirements obtained to concern with obtaining good properties of welding joints. Experimental research are executed in order to understand the phenomena in welding process of laser beam. Experimental research are expensive and low-labor so the research are focused on mathematical and numerical modeling of arising phenomena [1,2].

Numerical analysis of laser welding with consideration of analytical methods of analysis of phase transformations and mechanical properties of welded joints were presented. The analytical models concern to predicting of the structure of heat-affected zone (HAZ) on the basis of chemical composition. They can be used to a supplement to simulation results and for preliminary analysis of the material intended for welded

*Corresponding author: goszczynska@imipkm.pcz.pl

Reviewers: Zuzana Murčinková, Alžbeta Sapietová 
constructions. Empirical relationships presented in paper were determined by the chemical composition of analyzed steel and cooling rate between $800-500^{\circ} \mathrm{C}\left(\mathrm{t}_{8 / 5}\right)$. Phase composition and mechanical properties of each phases in weld and $\mathrm{HAZ}$ were predicted on the basis of analytical methods. Laser welded flat is used in numerical simulations in ABAQUS. Mathematical model of volumetric welding source is used in the calculations. Mechanical properties of welded joint were performed on the basis of numerically obtained phase composition and analytically obtained mechanical properties of each phases.

\section{Analytical methods of determining phase transformations and mechanical properties of welded joint}

Material during welding changes its thermo-physical and mechanical properties due to changing temperature field in a wide range. The most various material properties occur in the heat affected zone (HAZ). In this area a large variety of structures occurs conditioned by thermal cycles as a result of phase transformations in solid state.

Analytical models concern prediction of HAZ structure on the basis of chemical composition of steel, elaboration of simplified CCT diagrams and estimation of mechanical properties of HAZ of welded joints [3-7]. Analytical formulas are determined using the statistical analysis of results of experimental studies for a certain group of materials. The analytical relationships used in this paper concern wieldable low carbon and high strength steels, which included the S355 steel. Chemical composition of analyzed steel was shown in Table 1. Methods to the building simplify CCT diagrams for different kind of steel were by authors $[3,4,8]$.

Table 1. Chemical composition of S355 steel [\%]

\begin{tabular}{|c|c|c|c|c|c|c|c|c|}
\hline Steel & $\mathbf{C}$ & $\mathbf{M n}$ & $\mathbf{S i}$ & $\mathbf{P}$ & $\mathbf{S}$ & $\mathbf{A l}$ & $\mathbf{C r}$ & $\mathbf{N i}$ \\
\hline S355 & 0.19 & 1.05 & 0.20 & 0.028 & 0.02 & 0.006 & 0.08 & 0.11 \\
\hline
\end{tabular}

Dilatometric research on high strength steel was performed in order to verify the CCT diagram of austenite transformation obtained by using analytical relationships and to evaluate their usefulness. Dilatometric research was performed on the DIL805 Bahr Thermoanalyse $\mathrm{GmbH}$ dilatometer. Austenitization temperature $T_{A}=1200^{\circ} \mathrm{C}$ and heating rate $100 \mathrm{~K} / \mathrm{s}$ were assumed in dilatometric research as well as different cooling rates simulating thermal cycles in welding [9]. Analitycally and experimentally obtained CCT diagrams and phase volume fractions were presented in Figure 1 and 2. 


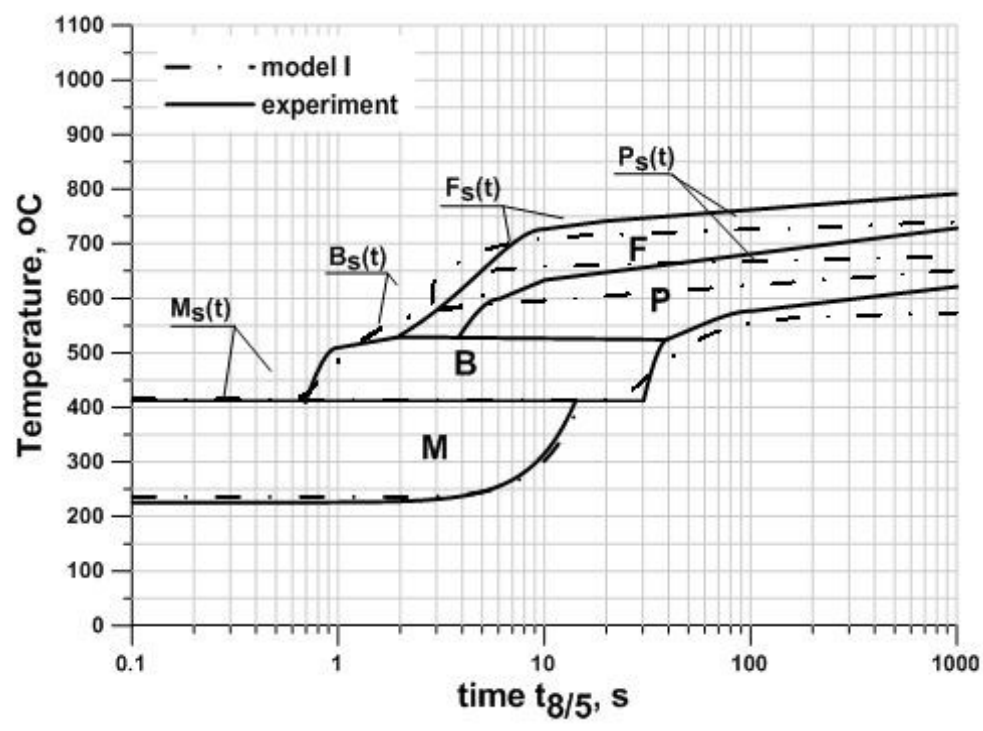

Fig. 1. Analytically and experimentally CCT diagram of S355 steel

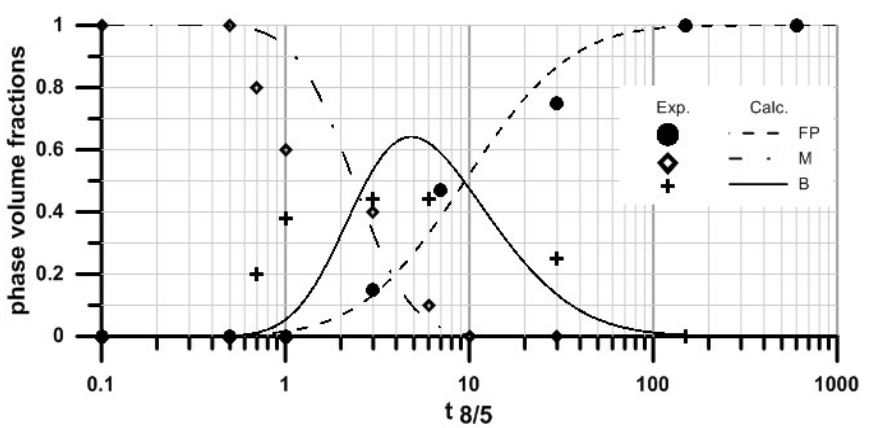

Fig. 2. Analytically and experimentally phase volume fraction of S355 steel

Mechanical properties of HAZ can be determined from the structural composition and mechanical properties of each structure. If the phase composition in the heat affected zone is known, more specifically contribution of each structure and properties of structural components $W_{i}$, there is a possibility to approximately predict properties of the entire zone $[3,4,6]$.

$$
W=\sum_{i=M, B, F, P} W_{i} \eta_{i}
$$

where: $W$ can be hardness, yield strength, tensile strength, impact strength, elongation and contraction.

Many dependencies are discussed in the literature $[1,2,5,6]$, which can determine mechanical properties such as: $\mathrm{R}_{\mathrm{e}}, \mathrm{R}_{\mathrm{m}}, \mathrm{A}_{5}, \mathrm{Z}, \mathrm{KCU}$ and $\mathrm{HV}$. Property of each phase are defined on the base of chemical composition, whereas contributions of each phase are defined on the base of experiment or numerical simulations.

Yield strength $\left(R_{e i}\right)$ and Tensile strength $\left(R_{m i}\right)$ of each phase: ferrite-pearlite, martensite and bainite can be determined with a high probability by Kasatin and Seyffart equations [4]: 


$$
\begin{aligned}
& \operatorname{Re}_{F P}=187+92 C+47 M n+90 \mathrm{~V} \\
& \operatorname{Re}_{M}=602+2150 C+500 M o \\
& \operatorname{Re}_{B}=500+460 C-120 C^{2}+150 \mathrm{~V}+360 M o \\
& R m_{F P}=297+1360 C+60 M n+140 \mathrm{~V} \\
& R m_{M}=798+3215 C \\
& R m_{B}=590+960 C+39.7 M n+200 \mathrm{~V}
\end{aligned}
$$

Hardness $\left(H V_{i}\right)$ of individual structural components can be defined by [3] as a function of chemical composition and velocity $v_{8 / 5}\left(v_{8 / 5}=(800-500) / t_{8 / 5}\right)$ :

$$
\begin{aligned}
& H V_{F P}=42+223 C+53 S i+30 M n+12.6 N i+7 C r+19 M o+ \\
& +(10-19 S i+4 N i+8 C r+130 V) \log v_{8 / 5} \\
& H V_{M}=127+959 C+27 S i+11 M n+8 N i+16 C r+21 \log v_{8 / 5} \\
& H V_{B}=-323+185 C+330 S i+153 M n+65 N i+144 C+ \\
& +191 M o+(89+53 C-55 S i-22 M n-10 N i-20 C r-33 M o) \log v_{8 / 5}
\end{aligned}
$$

Elongation $\left(\mathrm{A}_{\mathrm{i}}\right)$ and contraction $\left(\mathrm{Z}_{\mathrm{i}}\right)$ for structure components can be defined by [3] as a function of steel chemical composition and time $t$, where $t$ is the cooling time between temperatures $800^{\circ} \mathrm{C}$ and $500^{\circ} \mathrm{C}$ :

$$
\begin{aligned}
& A_{M}=12.267 C^{2}-1.5 M n+0.76 \ln t \\
& A_{B}=21.3-35.6 C-4.0 M n-5.0 \mathrm{~V}+1.84 \ln t \\
& A_{F P}=36.5-127 C+153 C^{2}-1.16 M n+8.0 \mathrm{~V}+0.66 \ln t \\
& Z_{M}=48.5-158 C+116 C^{2}-0.98 \ln t \\
& Z_{B}=53.3-132 C+103 C^{2}-5.1 M n-10 V+3.4 \ln t \\
& Z_{F P}=65.4-88 C-82 C^{2}-6.7 M n+18 V+0.6 \ln t
\end{aligned}
$$

\section{Exemplary of prediction of mechanical properties in welded joint}

Numerical analysis of thermal phenomena occurring during laser beam welding was carried out using the commercial Abaqus FEA program based on the finite element method $[10,11]$. The laser beam butt-welding of S355 steel sheets with dimensions $150 \times 15 \times 4 \mathrm{~mm}$ was considered. Variables with temperature thermo-physical properties and properties such as: laser beam power $Q=3.2 \mathrm{~kW}$, welding speed $v=1.0 \mathrm{~m} / \mathrm{min}$, the beam radius $r_{0}=1 \mathrm{~mm}$, depth penetration $s=7 \mathrm{~mm}$ were used in numerical calculations.

The analysis of thermal phenomena is made on the basis of the numerical solution of energy conservation equation together with Fourier law [12-15] using finite element method (FEM). The temperature field expressed in the criterion of weighted residuals method is described by the following equation:

$$
\int_{V} \rho \frac{\partial U}{\partial t} \delta T d V+\int_{V} \frac{\partial \delta T}{\partial x_{\alpha}} \cdot\left(\lambda \frac{\partial T}{\partial x_{\alpha}}\right) d V=\int_{V} \delta T q_{V} d V+\int_{S} \delta T q_{S} d S
$$


where: $\lambda$ is a thermal conductivity $[\mathrm{W} / \mathrm{mK}], U$ is the internal $[\mathrm{J} / \mathrm{kg}], q_{v}$ is the capacity of the laser beam power $\left[\mathrm{W} / \mathrm{m}^{3}\right], T=T(x, t)$ is a temperature $[\mathrm{K}], q_{s}$ is a density of heat flux $\left[\mathrm{W} / \mathrm{m}^{2}\right], T$ is a partial differential of $\mathrm{T}$.

Equation (7) expressed in the criterion of weighted residuals method and is completed by the initial condition and boundary conditions of Dirichlet, Neumann and Newton type with the heat loss due to convection and radiation [8]. To describe distribution of power of laser beam was used Cylindrical-Power-Normal model of heat source (C-P-N) [16]:

$$
Q_{2}(r, z)=\frac{k K_{z} Q_{L}}{\pi\left(1-e^{\left(K_{z} s\right)}\right)} e^{-\left(k r^{2}+K_{z} z\right)}(1-u(z-s))
$$

where: $Q_{L}$ is a power of the heat source [W], $r_{0}$ is radius of laser beam [m], $r=\sqrt{x^{2}+y^{2}}$ is current radius [m], $K_{z}=3 / s$ is exponent of a power of heat $\left[\mathrm{m}^{-1}\right], k=3 / r_{0}^{2}$ is source concentration factor $\left[\mathrm{m}^{-2}\right]$, and $s$ is depth penetration of beam $[\mathrm{m}], \mathrm{t} u(z-s)$ is Heaviside function.

During the numerical simulation in the ABAQUS FEA program, two additional numerical procedures, HETVAL and UEXPAN, were used for the determination of volume fractions. In addition, CCT and CTA diagram of S355 steel were interpolated In UEXPAN procedure. Cross section of analyzed welding joint for selected distance in the welding line $(\mathrm{x}=75 \mathrm{~mm})$ was presented in Figure 3. In addition, was marked boundary of individual zones: continuous line showed the weld zone $\left(\mathrm{T}_{\mathrm{L}} \approx 1527^{\circ} \mathrm{C}\right)$, dotted line showed boundary of heat affected zone $\left(T_{g} \approx 727^{\circ} \mathrm{C}\right)$.

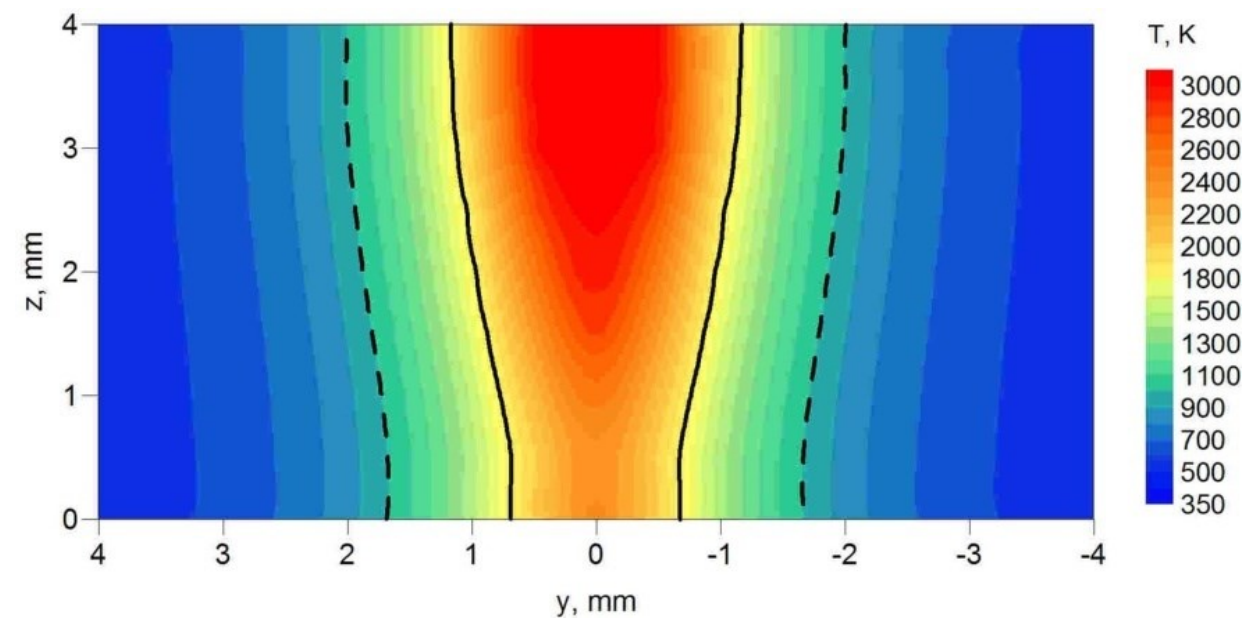

Fig. 3. Temperature field in the cross section of welded joint

Structural composition of welded joint in the cross section was determined on the basis on the numerically determined temperature distribution. Results of numerical analysis of phase composition of welded joint were presented in Figure 4. 


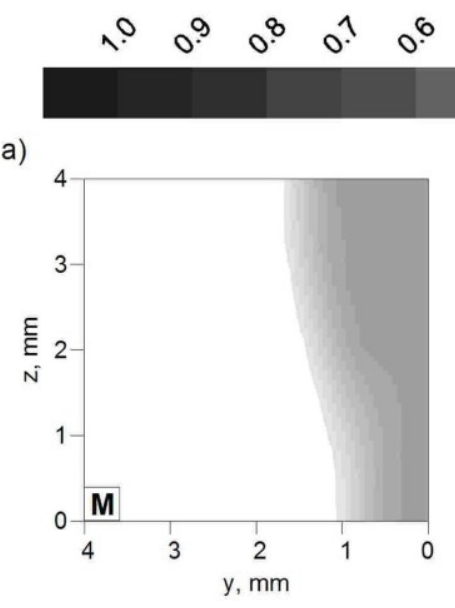

b)

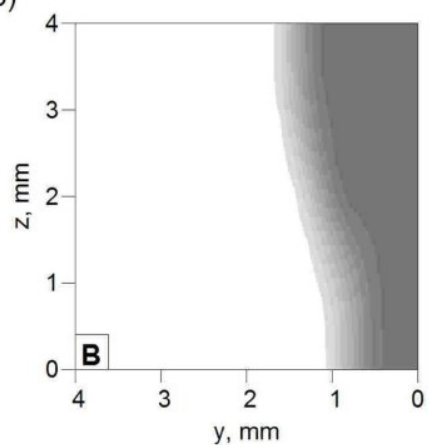

c)
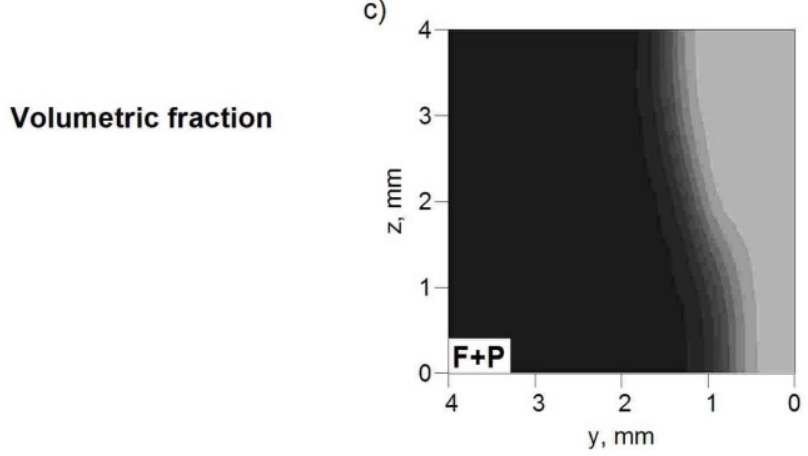

Fig. 4. Numerically estimated phase composition in weld and HAZ,

a) martensite, b) bainite, c) fearite+pearlite

Prediction of mechanical properties in weld and HAZ of welding joint was performed on the basis of relationships (1-6) and numerically obtained phase volume fraction. Distributions of mechanical properties in the cross section of analyzed steel were presented in Figures 5 to 7.
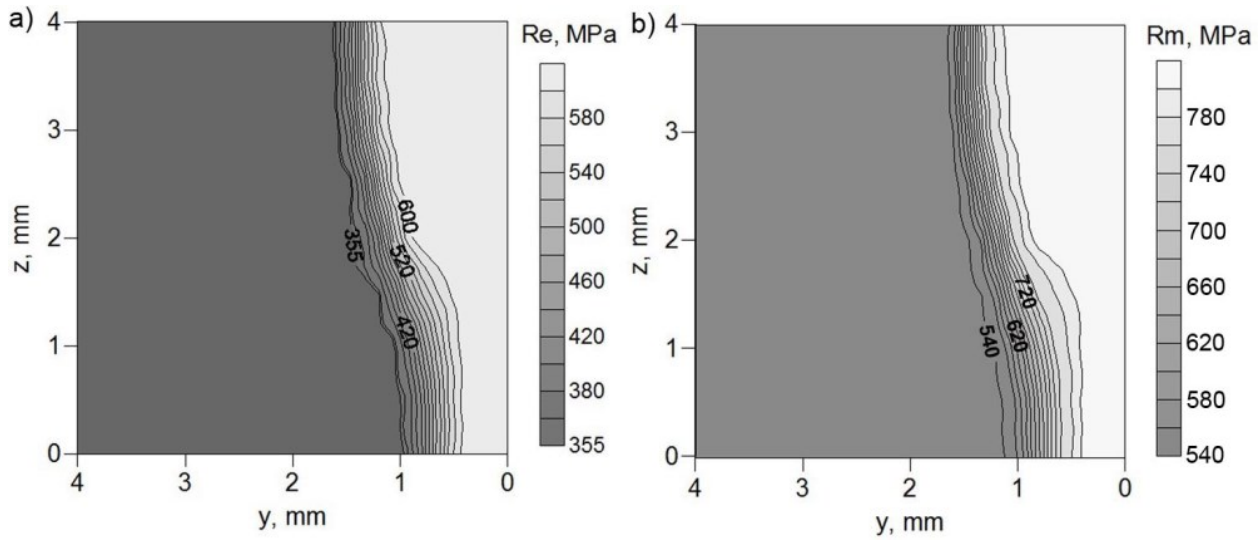

Fig. 5. Distribution of: a) Yield strength $\left(R_{e}\right)$, b) Tensile strength $\left(R_{m}\right)$ 

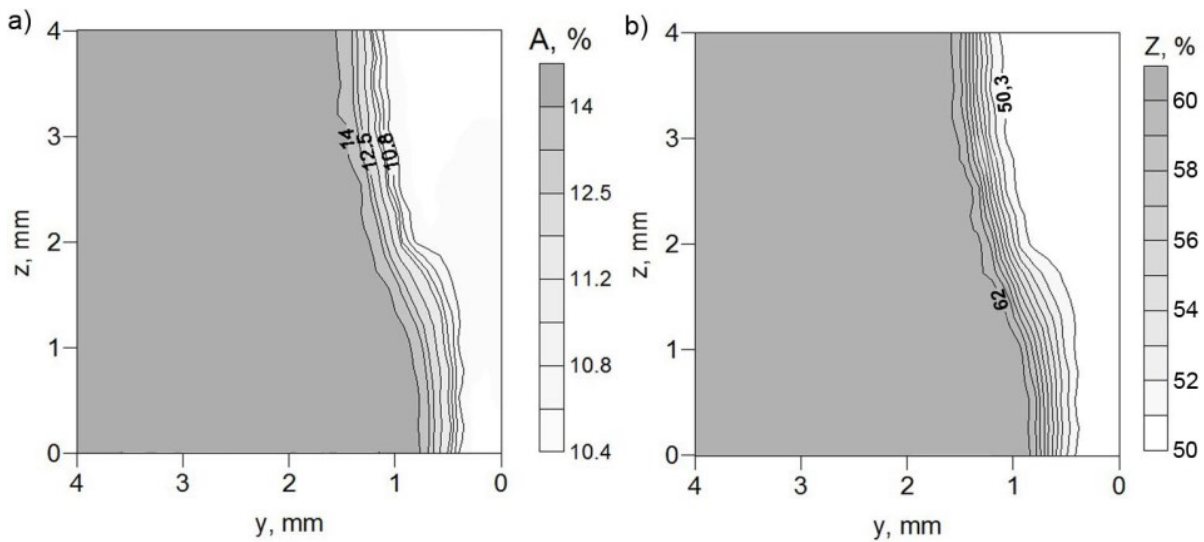

Fig. 6. Distribution of: a) elongation (A), b) contraction (Z)

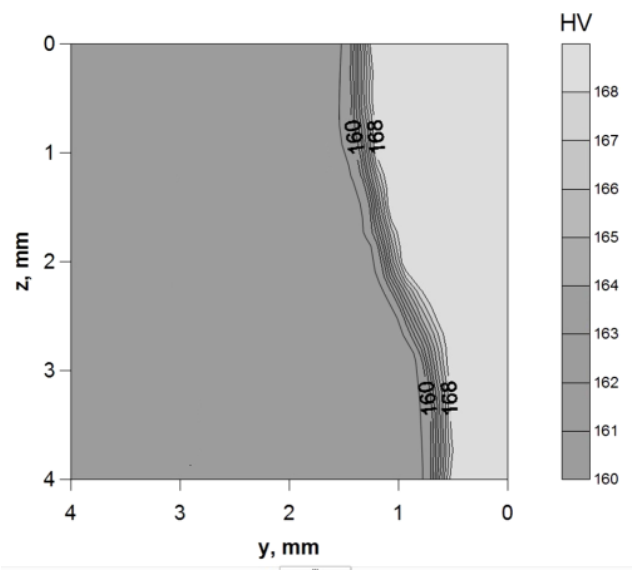

Fig. 7. Hardness distribution (HV)

\section{Conclusions}

The usefulness of analytical methods used to prediction the structure and mechanical properties in welded joint is assessed in this work. Analytical CCT diagram of S355 steels was built which verified by experiment. Phase volume fraction: ferrite, pearlite, bainite and martensite were determined. On the basis on analytical phase volume fraction performed a prediction of mechanical properties of welded joints. The numerical model build in the Abaqus FEA, which reflects laser beam welding, has been completed by additional HETVAL and UEXPAN subroutines which allow to define of phase volume fraction in the cross section of weld. Based on the numerically estimated contribution of individual phase transformations and known analytical models to determine the mechanical properties of individual structures, the $\mathrm{R}_{\mathrm{e}}, \mathrm{R}_{\mathrm{m}}, \mathrm{A}, \mathrm{Z}$ and $\mathrm{HV}$ distributions in the cross section of the welded joint of S355 steel were predicted.

Mechanical properties obtained using analytical methods can be applied for the preliminary analysis of material properties intended for different welded constructions. They can also be used as input data in numerical analysis of stresses and deformations in welded elements, substituting expensive experimental research in this field. 


\section{References}

1. W. Piekarska, M. Kubiak, Z. Saternus, Numerical Modelling of Thermal and Structural Strain in Laser Welding Process. Archives of Metallurgy and Materials (4), 1219-1227 (2012)

2. W. Piekarska, Z. Saternus, M. Kubiak, T. Domański, Numerical Modelling of Stress State and Deformations in Laser Butt-Welded Sheets Made of X5CrNi18-10 Steel. METAL 2015 Proceedings, Brno, Czech Republic, 736-741 (2015)

3. J. Mikuła, Analityczne metody oceny spawalności stali. Zeszyty naukowe Mechanika 85, Politechnika Krakowska, Kraków (2001)

4. W. Piekarska, Numerical and Experimental Study of Phase Transformations in Welding Processes. Archives of Metallurgy and Materials (4), 2559-2568 (2015)

5. P. Seyffart, O.G. Kasatkin, Mathematisch-statistische Beschreibung der Austenitumwandlung in der Wärmeeinflußzone. Schweißtechnik 29, 117-119 (1979)

6. P. Seyffart, O.G. Kasatkin, Rascentnye modeli dla ocenki mechaniceskich svojstv metalla ZTV pri svarke nizkoegirovannych stalej. Proc. Int. Conference mechanical Modelling and Information Technologies in Welding and Related Processes, ed. V.I. Makhnenko, Katsiveli, Crimea, E.O. Paton Welding Inst. of NAS of Ukraine, Kiev 103-106 (2002)

7. P. Seyffart, O.G. Kasatkin, Interpolâcionnye modeli dlâ ocenki fazovogo sostava zony termičeskogo vliâniâ pri dugovoj svarke nizkolegirovannyh stalej. Avtomat. Svarka 1, 7-11 (1984)

8. J. Brózda, J. Pilarczyk, M. Zeman, Spawalnicze wykresy przemian austenitu CTP-S. (Wydawnictwo ŚLĄSK, Katowice, 1983)

9. W. Piekarska, M. Kubiak, Theoretical investigations into heat transfer in laser-welded steel sheets. J. Therm. Anal. Calorim. 110, 159-166 (2012)

10. T. Domanski, A. Sapietova, M. Saga, Application of Abaqus software for the modeling of surface progressive hardening. Procedia Engineering 177, 64-69 (2017)

11. A. Bokota, T. Domanski, Modelling And Numerical Analysis Of Hardening Phenomena Of Tools Steel Elements. Archives Of Metallurgy And Materials 54 (3), 575-587 (2009)

12. SIMULIA Dassault System, Abaqus theory manual. Version 6.7 (2007)

13. L. Sowa, Effect of steel flow control devices on flow and temperature field in the tundish of continuous casting machine. Archives of Metallurgy and Materials 60 (2A), 843-847 (2015)

14. M. Sapieta, V. Dekýš, A. Sapietová, Thermal-stress analysis of beam loaded by 3 point bending. Procedia Engineering 136, 216-219 (2016)

15. L. Jakubovičová, A. Gašparec, P. Kopas, M. Sága, Optimization of the induction heating process in order to achieve uniform surface temperature. Procedia Engineering 136, 125-131 (2016)

16. E. Ranatowski, Uwagi o modelowaniu procesów cieplnych przy użyciu skoncentrowanych źródeł energii. Przegląd Spawalnictwa 8-10, 152-155 (2002) 